\title{
Impact of Magnetically Treated Water on Compressive and Flexural Strength of Concrete
}

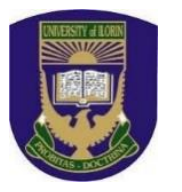

\author{
K. O. Yusuf, T. D. Akpenpuun*, S. O. David, C. H. Oluwayemi \\ Department of Agricultural and Biosystems Engineering, University of Ilorin, Ilorin, Nigeria.
}

\begin{abstract}
This study was conducted to determine the effect of Magnetically Treated Water (MTW) on compressive, flexural and impact strengths of concrete. The compressive strength, flexural and impact test were determined using $100 \mathrm{~mm}$ cube, 100x100x500 mm, 100mm diameter and $64 \mathrm{~mm}$ high, respectively. MTW was produced by passing water through magnetic flux densities: $400\left(\mathrm{~T}_{1}\right), 600\left(\mathrm{~T}_{2}\right), 800\left(\mathrm{~T}_{3}\right)$ and $997 \mathrm{G}\left(\mathrm{T}_{4}\right)$ as the treatments while Non-MTW (NMTW, $\mathrm{T}_{0}$ as control). The ratio of cement, fine aggregate and coarse aggregate was 1:2:4 and curing duration for the concretes were 7, 14, 21 and 28 days. Universal Testing Machine was used to determine the compressive and flexural strengths while drop weighing impact tester was used for determining the impact strength of the concrete. The mean forces at peak to break the concrete cured for 28 days for $\mathrm{T}_{0}, \mathrm{~T}_{1}, \mathrm{~T}_{2}, \mathrm{~T}_{3}$ and $\mathrm{T}_{4}$ were 106.79, 121.25, 114.15, 107.06 and $196.68 \mathrm{kN}$, while the compressive strengths were 10.68, 12.13, 11.42, 10.71 and $19.67 \mathrm{Nmm}^{-2}$, respectively. The maximum compressive, flexural and impact strengths of the concrete were 84.17, 22.37 and $96.93 \%$, respectively. The effect of MTW was statistically significant on compressive, flexural and impact strengths and is recommended for use.
\end{abstract}

KEYWORDS: Concrete, mechanical strength, magnetized water, failure, flux densities

[Received Feb. 6, 2021; Revised Aug. 12, 2021; Accepted Sept. 30, 2021]

Print ISSN: 0189-9546 | Online ISSN: 2437-2110

\section{INTRODUCTION}

Concrete and sandcrete blocks are commonly used for the construction of residential buildings, crop storage buildings, farm buildings for man and animals, water storage structures and as material for canal lining. Concrete comprises aggregate (sand and gravel or crushed granite) and pastes (cement and water) that are mixed together to form a strong rock-like mass called concrete which could be used in the construction of farm structures and residential buildings. The paste binds the aggregate together and hardening is as a result of a chemical reaction between the cement and water during the time of curing which makes the concrete strong (Patil and Pathak, 2016; Akpenpuun et. al., 2019). Curing is a process through which the strength and durability of concrete are improved by providing adequate moisture (water) for the concrete to have uninterrupted hydration at the desired temperature and over a given period (7 - 28 days). Sandcrete block comprises the fine aggregate (sand), cement and water. Cases of the collapse of buildings are common in some developing countries like Nigeria which could lead to loss of lives and properties. The collapse of buildings is usually due to failure of the materials (concrete and sandcrete blocks) used for the construction. There is need for simple, economical and environmentally friendly methods for improving the strength of concrete and the block that are used for the construction of residential buildings and storage structures to prevent the ugly cases of collapse of buildings in the society.
Magnetically treated water also called magnetized water (magnetic water) has been used in some fields like agriculture for improving the nutritional quality of tomato and high crops yield, in dairy production, health care and wastewater treatment (Karam and Al-Shamali, 2013; Yusuf and Ogunlela, 2016; Yusuf and Ogunlela, 2017). The technology of magnetic treatment of water could be used to improve the strength of materials needed for the construction of farm structures. Albahrani (2018) stated that the compressive strength of concrete produced using water treated with magnetic field for 28 days increased by $26.2 \%$ while Kiranmai and Rao (2018) reported that the compressive strength of concrete (M30 grade) using magnetized water treated for 24 hours increased by $38.1 \%$ after curing for 7 days. Shynier et al. (2012) also reported that magnetically treated water used for mixing the concrete improved the compressive strength of the concrete by $10-22 \mathrm{Nmm}^{-2}$. Nilson (1987) also stated that magnetically treated water improved the mechanical properties of concrete without adding any admixture in the concrete mix and it increased the strength of the concrete by $10-22 \%$. Ahmed (2009) concluded that the magnetic flux density, the velocity of flow of water during the treatment and treatment time required for concrete strength increase of $10-20 \%$ is $12,000 \mathrm{G}$ (1.2T), $0.71 \mathrm{~m} / \mathrm{s}$ and $4,500 \mathrm{sm}^{-3}\left(4.5 \mathrm{sL}^{-1}\right)$, respectively. Reddy et al. (2014) concluded that magnetized water increased the compressive strength of concrete by 55\% and this happened because the effect of magnetic field on water reduced the 
bonding angle of water molecules from $104.5^{\circ}$ to $103^{\circ}$, reduced the surface tension and broke clusters of large molecules into smaller clusters of molecules. These changes aided the penetration of water into cement particles and enhances proper hydration (Nan Su et al., 2003).

Magnetized water is produced by allowing water to flow through a pipe surrounded by permanent magnets that would produce the magnetic field. The impact of magnetic field on the water would reduce the surface tension of the water and increase the solubility of the water. The magnetic field breakdown the water molecules into smaller water molecule clusters and restructure the water clusters into well-organized molecules and this makes magnetized water to be easily absorbed by plant and other materials (Malathy et al., 2017). Kronenberg (1985) pointed out that activation of water treatment by magnetic field depends on the magnetic flux density (strength of the magnet), duration of exposure, the velocity of flow of the water through the magnetic field and quantity of water to be magnetized. Maheshwari and Grewal (2009) reported that magnetic flux density ranging from 350 to $1,360 \mathrm{G}$ (measured inside the pipe where water is flowing) is adequate for magnetic water treatment. Podlesny et al. (2004) pointed out that for effective magnetic treatment, the detention period of water in the magnetic field should be at least $15 \mathrm{~s}$, while Aladjadjiyan (2007) reported that a detention period of 1-10 minutes is required for effective treatment of water in a magnetic field.

The time used by some researchers for producing magnetized water for concrete was high ranging from 24 hours to 28 days and the long time may not be economical for producing concrete in developing countries like Nigeria. Kiranmai and Rao (2018) stated that 24 hours was effective for producing magnetized water and Albahrani (2018) reported that magnetized water for concrete production was treated by a magnetic field in 28 days. Vinod-Kumar et al. (2017) used $24,48,72$ and 96 hours for producing magnetized water. In this new study, circulation method of magnetic treatment of water was used in which water flows through a magnetic field for a short period of about $20-110 \mathrm{~s}$. This duration (20 - $110 \mathrm{~s}$ ) for magnetization of water for concrete and block production is cheap, simple, time-efficient, practicable and could be adopted by concrete producers. The hydration of cement $\left(\mathrm{Ca}_{3} \mathrm{SiO}_{5}\right)$ by water $\left(\mathrm{H}_{2} \mathrm{O}\right)$ to form calcium silicate hydrate $\left(\mathrm{Ca}_{3} \mathrm{Si}_{2} \mathrm{O}_{7} .3 \mathrm{H}_{2} \mathrm{O}\right)$ and calcium hydroxide $\left(\mathrm{Ca}(\mathrm{OH})_{2}\right)$ which subsequently forms a strong crystalline structure called concrete (Shynier et al., 2012). The reaction by the hydration process of cement and water is shown in Eq. (1).

$$
2 \mathrm{Ca}_{3} \mathrm{SiO}_{5}+6 \mathrm{H}_{2} \mathrm{O} \rightarrow \mathrm{Ca}_{3} \mathrm{Si}_{2} \mathrm{O}_{7} .3 \mathrm{H}_{2} \mathrm{O}+3 \mathrm{Ca}(\mathrm{OH})_{2}
$$

The objective of this study is to determine the effect of magnetically treated water on the strength of the concrete (force at peak to break the concrete), compressive strength, flexural and impact strength of concrete produced using magnetically treated water, compare with the concrete using non-magnetically treated water. Figures $1 \mathrm{a}$ and $1 \mathrm{~b}$ show water cluster of magnetically treated water and non-magnetically treated water, respectively.

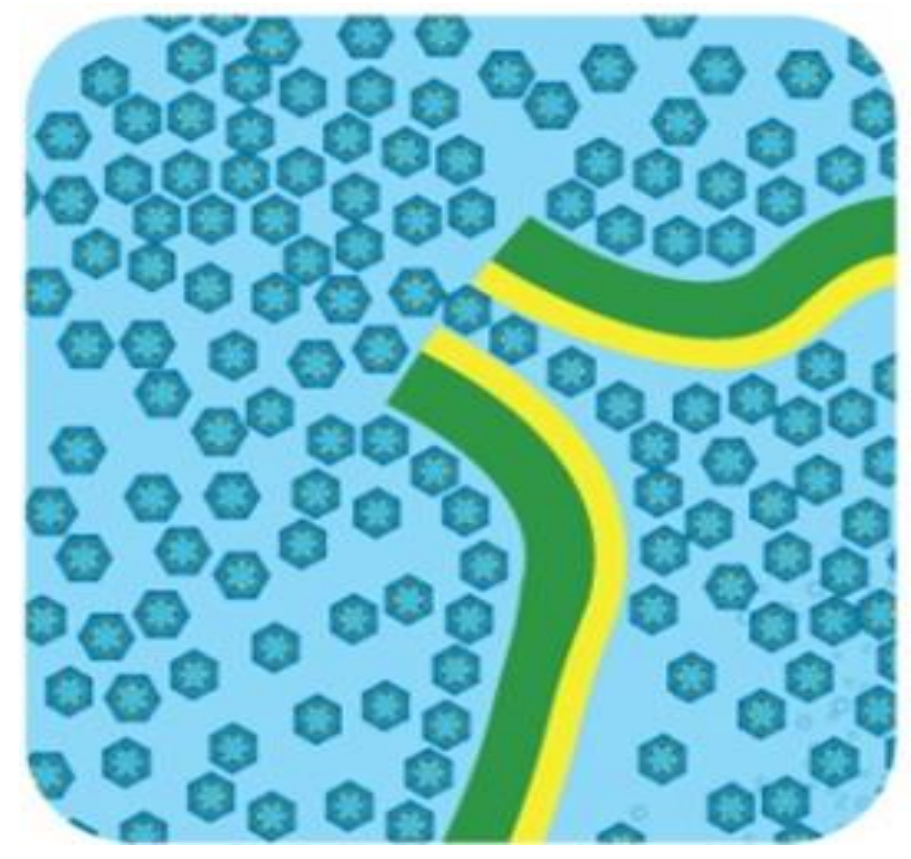

Figure 1a: Magnetized water.

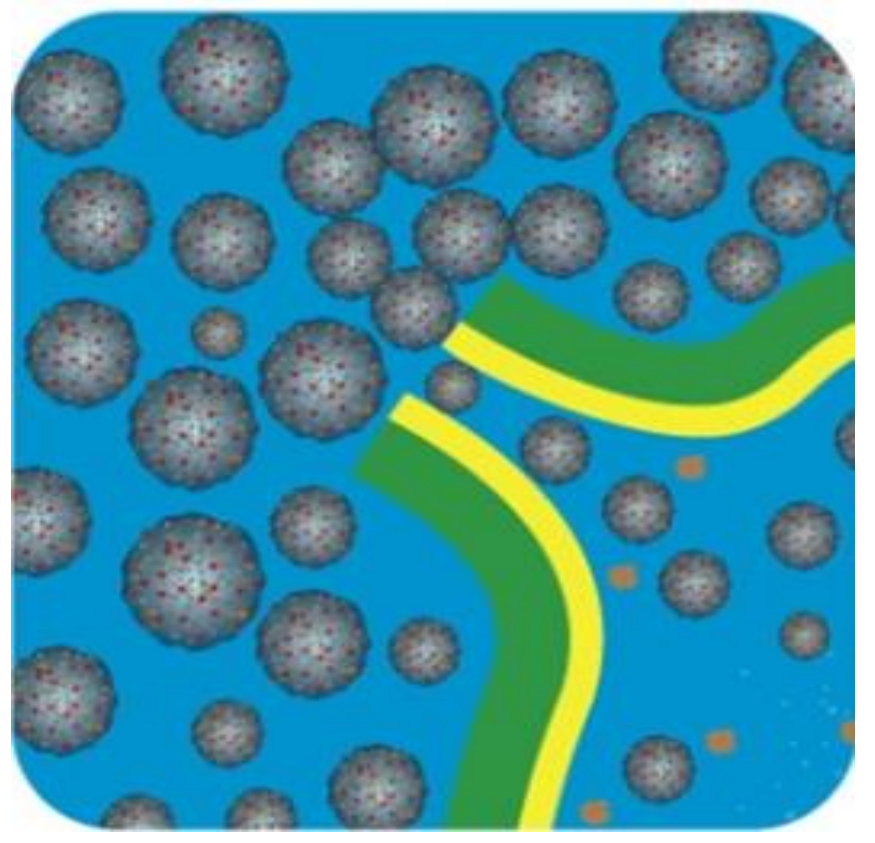

Figure 1b: Non-magnetized water (Malathy et al., (2017).

\section{MATERIALS AND METHODS}

\section{A. Production of Concrete, Determination of Compressive And Flexural Strengths}

A $100 \times 100 \times 100 \mathrm{~mm}$ cube mould was used to produce the concrete that was needed for a compressive test. The materials used for the concrete were sand sieved through 4.75 $\mathrm{mm}$ sieve, crushed granite sieved through $12 \mathrm{~mm}$ sieve, Portland cement and water. The ratio of cement, sand (fine aggregate) and crushed granite (coarse aggregate) were 1:2:4 by weight following EN BS 812-5 1990. The concrete dimension for the flexural test was $150 \times 150 \times 500 \mathrm{~mm}$ while 
dimension of $64 \mathrm{~mm}$ diameter and $100 \mathrm{~mm}$ high concrete was used for the impact resistance test. The dimensions of the concretes used for the compressive strength, flexural text and impact test were chosen based on the requirement of the testing machine. Magnetic flux densities of 400, 600, 800 and 997 Gauss (G) were used to treat the water. The magnetic flux density inside the hose through which the water flows was measured using a gaussmeter (Model GM-2 by Alpha Lab Inc). The retention time of water in the magnetic field was $110 \mathrm{~s}$ and circulation flow method were used. The same volume of magnetically treated water and non-magnetically treated water were used to mix the concrete. In the second experiment, the magnetic flux density of $997 \mathrm{G}$ was used but the time for treating the water by magnetic field were 20,30 and $60 \mathrm{~s}$. The compaction of the material in the mould was done following ENV 13670-1.

The concrete was removed after 24 hours of setting and samples of the concrete produced were submerged in a curing tank having water (non-magnetically treated water) and cured for 7, 14, 21 and 28 days. The samples of the concrete were tested using Universal Testing Machine (UTM, with model FT300CT by Testometric Company Limited, United Kingdom) at a speed of $10 \mathrm{~mm} / \mathrm{s}$. The compressive strength of the $100 \times 100 \times 100 \mathrm{~mm}$ cube was determined as shown in Figure 2 while the flexural strength was determined using the UTM as shown in Figure 3. In this study, all the experiments for each treatment were replicated 3 times and the mean result was obtained and presented in the results section.

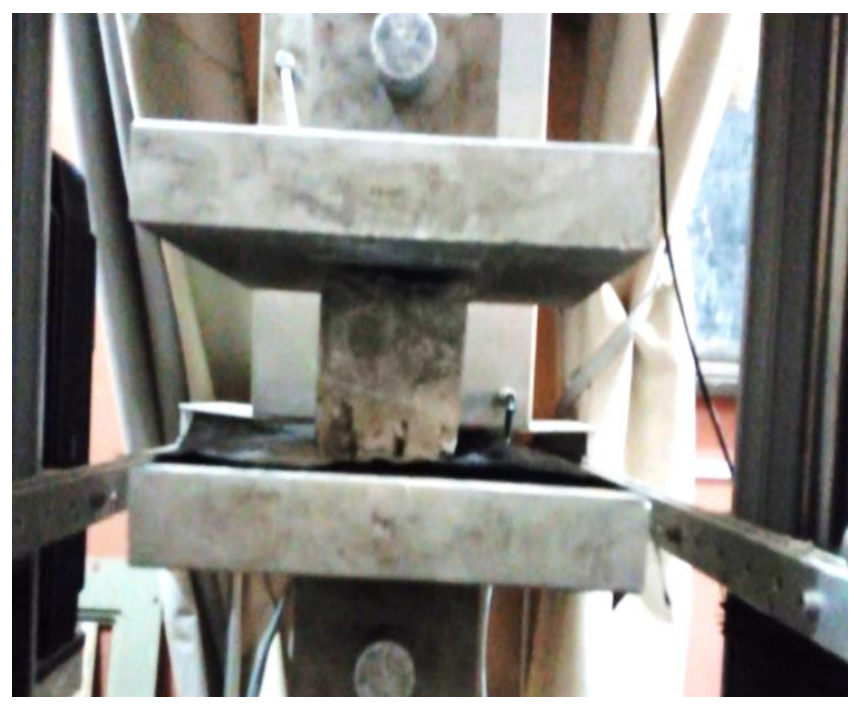

Figure 2: Determination of compressive strength of the concrete.

\section{B. Preparation of Magnetized Water}

The magnetized water was produced by allowing water to flow from a 50 litres reservoir placed at $0.60 \mathrm{~m}$ above the magnetic treatment unit that produced the required pressure head for the flowing water through the magnetic field. Circulation water flowing method was used in this study with water flowing through the magnetic field while ensuring that the flow of water and magnetic field are at $90^{\circ}$ to each other (using Fleming's Right-hand rule). Permanent magnet from loudspeakers was used in this study to generate the magnetic field and the strength of the magnets was measured using the gaussmeter (Model GM-2 by Alpha Lab Inc). Circulation flow method was used in this study because it was found to be effective in producing magnetized water than the static and single flow methods Chern (2012).

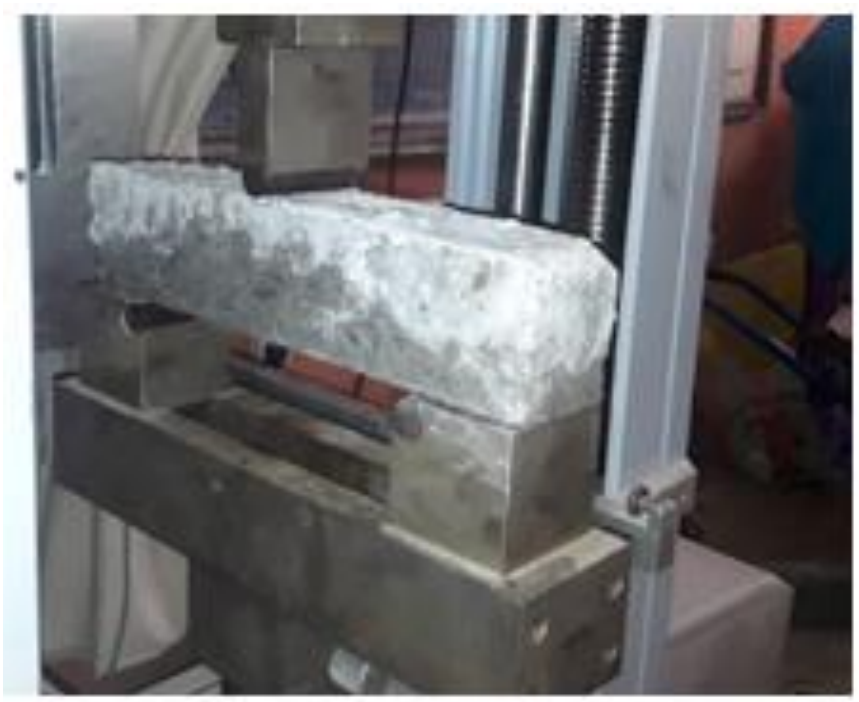

Figure 3: Determination of flexural strength of the concrete.

The magnetic field unit is $393 \mathrm{~mm}$ long and it takes $5 \mathrm{~s}$ for water to flow from the reservoir through the magnetic field to the treated water collector. The thickness of the housing of the magnetic treatment unit is adjustable for the desired hose diameter and this makes the selection of 400, 600, 800 and 997 $\mathrm{G}$ possible. The water was allowed to flow through the magnetic field for 4, 6, 12 and 22 times during the treatment and the corresponding retention time were 20,30, 60 and 110 s.

\section{Determination of Impact Resistance Test}

The impact resistance test of the concrete was done using Aggregate impact testing machine (Model TO - 456) shown in Figure 5. The impact energy from a load of mass $4536.2 \mathrm{~g}$ $(4.5362 \mathrm{~kg})$ with a velocity of $2.995 \mathrm{~ms}^{-1}$ on the concrete was based on kinetic energy (K.E) that could cause cracking or total failure when it falls on the concrete. The ability of the concrete to convert the kinetic energy to potential energy without cracking or failure is called impact resistance of the concrete. The kinetic energy required to break the concrete was computed using Eq. (2). The kinetic energy for 1 blow that cracked the concrete was $20.34 \mathrm{~J}$.

$$
K . E=\frac{N M V^{2}}{2}
$$

where $K . E$ is the kinetic energy required to break the concrete or impact resistance $(\mathrm{J}), N$ is the number of blows that cause failure, $M$ is mass of concrete $(\mathrm{kg})$ and $V$ is the velocity of drop of the concrete from the impact testing machine $\left(\mathrm{ms}^{-1}\right)$. 


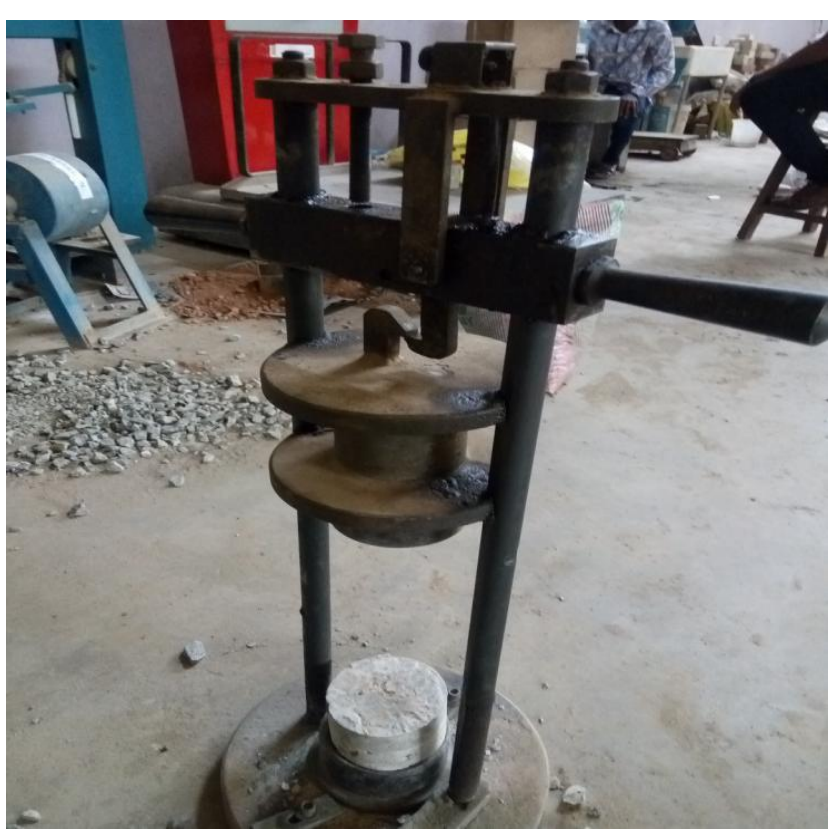

Figure 5: Aggregate impact testing machine.

\section{Statistical Analysis by Randomized Complete Block Design}

Statistical analysis was conducted to determine if the effect of magnetized water used to produce the concrete was statistically significant on the compressive and flexural strengths on the concrete $t$ using Randomized Complete Block Design (RCBD). In the first experiment, 5 x 4 RCBD layout was used while $4 \times 4$ RCBD was used in the second experiment. Sum of Square Treatment ( $\mathrm{SST}_{\mathrm{R}}$ ), Sum of Square Block (Curing time) $\left(\mathrm{SSB}_{\mathrm{C}}\right)$, Sum of Square Total $\left(\mathrm{SST}_{\mathrm{O}}\right.$ ), Correction Factor (C.F) and Sum of Square Error $\left(\mathrm{SS}_{\mathrm{E}}\right)$ were computed using Eq. (3), (4), (5), (6) and (7), respectively. The Analysis of Variance (ANOVA) was based on values obtained from Eqs. (3), (4), (5) and (7) given by Gomez and Gomez (1984).

$$
\begin{gathered}
S S T_{R}=\frac{\sum T_{i}^{2}}{t}-C . F \\
S S B_{C}=\frac{\sum B_{i}^{2}}{b}-C . F \\
S S T_{O}=\sum X_{i}^{2}-C . F
\end{gathered}
$$

$$
\begin{aligned}
& C . F=\frac{G^{2}}{N} \\
& S S_{E}=S S T_{O}-S S T_{R}-S S B_{C}
\end{aligned}
$$

where $T_{i}$ is the total value of each treatment, $\mathrm{t}$ is the number of the treatments used, $B$ is the total value of each block, $b$ is the number of the blocks, $X$ is the individual value of compressive strength or flexural strength for each treatment, $G$ is the total value of compressive strength for all the treatments during experiment and $N$ is the number of observations.

\section{E. Statistical Analysis by Paired T-Test}

A paired t-test statistical analysis was used to determine if the effect of MTW was statistically significant on the impact strength of the concrete. The mean, standard deviation, standard error and t-test value were determined using Eqs. (8), (9a) or (9b), (10) and (11), respectively as given by Montgomery (1998). The data used for the computation of the paired t-test as an illustration was obtained from Table 1. The calculated values of the t-test was compared with the value obtained from the t-distribution table to determine the significance of the treatment on the strength properties of interest.

$$
\begin{gathered}
\bar{d}=\frac{\sum x_{1}-x_{2}}{n} \\
\delta=\sqrt{\frac{\sum d^{2}-n(\bar{d})^{2}}{n-1}} \\
\delta=\sqrt{\frac{\sum(d-\bar{d})^{2}}{n-1}} \\
\delta_{E r}=\frac{\delta}{\sqrt{n}} \\
t_{c a l}=\frac{\bar{d}}{\delta_{E r}}
\end{gathered}
$$

where $\bar{d}$ is the mean of the difference from $x_{1}$ and $x_{2}, \Sigma \mathrm{d}$ is the summation of $\mathrm{d}, \mathrm{n}$ is the number of the observations, $\delta$ is the standard deviation, $\delta_{E r}$ is the standard error and $\mathrm{t}_{\mathrm{cal}}$ is the calculated value of $\mathrm{t}$ at $\alpha=5 \%$ significant level.

From Eqs. (8) and (9a), the values for $\bar{d}$ and $\delta$ are respectively obtained as 137.84 and 50.76, while 25.38 and 5.431 are obtained for $\delta_{E r}$ and $t_{\text {cal }}$ from Eqs. (10) and (11)

Table 1: Computation of paired t-test value using impact strength.

\begin{tabular}{lccc}
\hline MTW $\left(\mathbf{I}_{\mathbf{1}}\right)$ & $\mathbf{N M T W}\left(\mathbf{I}_{\mathbf{2}}\right)$ & $\mathbf{d}=\mathbf{I}_{\mathbf{1}} \mathbf{-} \mathbf{I}_{\mathbf{2}}$ & $\mathbf{d}^{\mathbf{2}}$ \\
\hline 94.92 & 27.12 & 67.80 & $4,596.84$ \\
176.28 & 33.90 & 142.38 & $20,272.06$ \\
198.21 & 39.00 & 159.21 & $25,347.82$ \\
223.74 & 40.68 & 183.06 & $33,510.96$ \\
$\mathrm{~N}=4$ & & $\sum \mathrm{d}=551.35$ & $\sum \mathrm{d}^{2}=83,727.68$ \\
\hline
\end{tabular}


respectively. Looking at $\mathrm{t}$-distribution table, the value of $\mathrm{t}_{\text {Table }}$ at $\alpha \leq 0.025$ and 3 degrees of freedom $=3.182$.

\section{RESULTS AND DISCUSSION}

The results of compressive strength and force at peak required to break the $100 \mathrm{~mm}$ cube of concrete produced in the first experiment using Magnetically Treated Water (MTW) that was treated with $400 \mathrm{G}\left(\mathrm{T}_{1}\right), 600 \mathrm{G}\left(\mathrm{T}_{2}\right), 800 \mathrm{G}\left(\mathrm{T}_{3}\right)$ and $997 \mathrm{G}\left(\mathrm{T}_{4}\right)$ in $110 \mathrm{~s}$ and Non-Magnetically Treated Water (NMTW) are shown in Table 2. The ANOVA for the effect of MTW on the compressive strength of concrete using RCBD in the first experiment is presented in Table 3. Table 4 shows the effect of magnetically treated water on the force at peak and compressive strength required to break the concrete in the second experiment using $997 \mathrm{G}$ in which the water was treated for 20,30 and 60sTable 5 shows the ANOVA of the effect of MTW on the compressive strength of concrete using RCBD in the second experiment. The result of the flexural strength test on $150 \times 150 \times 500 \mathrm{~mm}$ concrete and the force at peak required to break the concrete using MTW and NMTW in the first experiment are shown in Table 6 while Table 7 shows the ANOVA of the effect of MTW on the flexural strength of the concrete.

Table 8 shows the results of the impact resistance test on $64 \mathrm{~mm}$ diameter and $100 \mathrm{~mm}$ high concrete produced using MTW treated with $997 \mathrm{G}$ treated in $110 \mathrm{~s}$ compared with concrete using NMTW. From Table 2, NMTW concrete (To) had the lowest force at peak and also had the highest compressive strength required to break the concrete while the strongest concrete was MTW with the highest magnetic flux density of $997 \mathrm{G}$.

From Table 2, $997 \mathrm{G}$ was more effective in producing magnetized water and curing the concrete for 7, 14, 21- and 28days increased the compressive strength by $75.34,91.24$, 104.68 and $84.18 \%$, respectively. In the second experiment, the compressive strength of concrete produced using MTW treated with $997 \mathrm{G}$ for 60 seconds and cured for 21 and 28 days increased by 78.17 and $56.45 \%$, respectively.

The compressive strength and flexural strength obtained in this study were higher than the values obtained by other researchers which might be due to circulation flow method which was used in this study. The circulation flow method is more effective for producing MTW than the static flow method used by some researchers. The results obtained in this study agreed with the result obtained by other researchers that MTW increased the compressive strength of concrete and curing time of $7,14,21$ and 28 days also increased the strength of the concrete. The effect of MTW was statistically significant on the compressive, flexural strengths and impact resistance which agrees with the studies by Ahmed (2009); Parthiban et al. (2016); Kiranmai and Rao (2018), Nilson (1987) reported that magnetically treated water increased the strength of the

Table 2: Effect of magnetically treated water on the compressive strength of concrete.

\begin{tabular}{ccccccccccc}
\hline Curing & \multicolumn{3}{c}{ Force at peak to break the concrete (kN) } & \multicolumn{3}{c}{ Compressive strength (Nmm-2 } \\
day & $\mathrm{T}_{\mathrm{o}}$ & $\mathrm{T}_{1}$ & $\mathrm{~T}_{2}$ & $\mathrm{~T}_{3}$ & $\mathrm{~T}_{4}$ & $\mathrm{~T}_{\mathrm{o}}$ & \multicolumn{2}{c}{$\mathrm{T}_{1}$} & $\mathrm{~T}_{2}$ & $\mathrm{~T}_{3}$ \\
\hline 7 & 66.06 & 68.81 & 78.81 & 88.70 & 115.92 & 6.61 & 6.89 & 7.88 & 8.87 & 11.59 \\
14 & 73.05 & 88.63 & 97.07 & 105.50 & 139.76 & 7.31 & 8.86 & 9.71 & 10.55 & 13.98 \\
21 & 83.43 & 98.34 & 100.02 & 101.70 & 170.66 & 8.34 & 9.83 & 10.00 & 10.17 & 17.07 \\
28 & 106.79 & 121.25 & 114.15 & 107.06 & 196.68 & 10.68 & 12.13 & 11.42 & 10.71 & 19.67 \\
\hline
\end{tabular}

$\mathrm{T}_{0}=$ Concrete produced using non-magnetically treated water

$\mathrm{T}_{1}=$ Concrete produced using magnetically treated water with magnetic flux density $400 \mathrm{G}$

$\mathrm{T}_{2}=$ Concrete produced using magnetically treated water with magnetic flux density $600 \mathrm{G}$

$\mathrm{T}_{3}=$ Concrete produced using magnetically treated water with magnetic flux density $800 \mathrm{G}$

$\mathrm{T}_{4}=$ Concrete produced using magnetically treated water with magnetic flux density $997 \mathrm{G}$

Table 3 ANOVA for the effect of MTW on the compressive strength of concrete using RCBD.

\begin{tabular}{ccccc}
\hline Source of variation & $\begin{array}{c}\text { Degree } \\
\text { of freedom }\end{array}$ & $\begin{array}{c}\text { Sum } \\
\text { of Square }\end{array}$ & $\begin{array}{c}\text { Mean } \\
\text { Square }\end{array}$ & $\begin{array}{c}\text { Calculated } \\
\text { value of F }\end{array}$ \\
\hline Treatment & 4 & 130.94 & $\begin{array}{c}\text { Table } \\
\text { value of F } \\
\text { at } \mathbf{p} \leq \mathbf{1 \%}\end{array}$ \\
Curing day & 3 & 54.36 & 15.735 & 4.430 \\
Error & 12 & 200.52 & 1.26 .120 & $14.290^{\mathrm{S}}$ \\
Total & 19 & 10.554 & 5.010 \\
\hline
\end{tabular}

$\mathrm{S}=$ Effect was significant at $\mathrm{p} \leq 1 \%$

Table 4: Compressive strength of MTW concrete of water treated with 997 G.

\begin{tabular}{|c|c|c|c|c|c|c|c|c|}
\hline \multirow[t]{2}{*}{$\begin{array}{l}\text { Curing } \\
\text { day }\end{array}$} & \multicolumn{4}{|c|}{$\begin{array}{l}\text { Force at peak to break the concrete } \\
(\mathrm{kN})\end{array}$} & \multicolumn{4}{|c|}{ Compressive strength $\left(\mathrm{N} / \mathrm{mm}^{-2}\right)$} \\
\hline & NMTW & $\begin{array}{l}\text { MTW for } \\
20 \mathrm{~s}\end{array}$ & $\begin{array}{l}\text { MTW } \\
\text { for } 30 \mathrm{~s}\end{array}$ & $\begin{array}{l}\text { MTW for } \\
60 \mathrm{~s}\end{array}$ & NMTW & $\begin{array}{l}\text { MTW } \\
\text { for } 20 \mathrm{~s}\end{array}$ & $\begin{array}{c}\text { MTW for } \\
30 \mathrm{~s}\end{array}$ & $\begin{array}{l}\text { MTW for } \\
60 \mathrm{~s}\end{array}$ \\
\hline 7 & 42.45 & 70.53 & 99.75 & 115.85 & 4.25 & 7.05 & 9.97 & 11.59 \\
\hline 14 & 67.36 & 108.12 & 170.36 & 146.87 & 6.74 & 10.81 & 17.04 & 14.69 \\
\hline 21 & 87.52 & 113.34 & 150.91 & 155.89 & 8.75 & 11.34 & 15.09 & 15.59 \\
\hline 28 & 108.57 & 123.04 & 166.04 & 169.91 & 10.86 & 12.30 & 16.60 & 16.99 \\
\hline
\end{tabular}

NMTW = Non-magnetically treated water, MTW = Magnetically Treated Water 
Table 5: ANOVA for the effect of MTW on the compressive strength of concrete using RCBD in the second experiment.

\begin{tabular}{cccccc}
\hline Source of variation & \multicolumn{1}{c}{ Degree of freedom } & Sum of Square & Mean Square & Calculated value of F & Table value of F at $\mathbf{p} \leq \mathbf{1 \%}$ \\
\hline Treatment & 3 & 144.02 & 48.007 & $49.852^{\mathrm{S}}$ & 5.420 \\
Curing day & 3 & 78.43 & 26.143 & $27.147^{\mathrm{S}}$ & 5.420 \\
Error & 9 & 8.67 & 0.963 & & \\
Total & 15 & 231.12 & & & \\
\hline
\end{tabular}

$\mathrm{S}=$ Effect was significant at $\mathrm{p} \leq 1 \%$

Table 6: Effect of magnetically treated water on the flexural strength in the first experiment.

\begin{tabular}{ccccccccccc}
\hline \multirow{2}{*}{$\begin{array}{c}\text { Curing } \\
\text { Days }\end{array}$} & \multicolumn{4}{c}{ Force at Peak $(\mathbf{k N})$} & \multicolumn{4}{c}{ Flexural Strength $\left(\mathbf{N m m}^{-2}\right)$} \\
\cline { 2 - 11 } & $\mathbf{T}_{\mathbf{0}}$ & $\mathbf{T}_{\mathbf{1}}$ & $\mathbf{T}_{\mathbf{2}}$ & $\mathbf{T}_{\mathbf{3}}$ & $\mathbf{T}_{\mathbf{4}}$ & $\mathbf{T}_{\mathbf{0}}$ & $\mathbf{T}_{\mathbf{1}}$ & $\mathbf{T}_{\mathbf{2}}$ & $\mathbf{T}_{\mathbf{3}}$ & $\mathbf{T}_{\mathbf{4}}$ \\
\hline 7 Days & 10.06 & 10.49 & 10.26 & 10.64 & 11.16 & 7.54 & 7.87 & 7.70 & 7.98 & 8.37 \\
14 Days & 11.21 & 11.12 & 11.29 & 11.45 & 11.95 & 8.41 & 8.34 & 8.30 & 8.53 & 8.96 \\
21 Days & 11.48 & 11.66 & 12.59 & 12.41 & 12.99 & 8.78 & 8.75 & 9.44 & 9.31 & 9.74 \\
28 Days & 11.89 & 12.01 & 12.75 & 13.13 & 14.62 & 8.75 & 9.01 & 9.56 & 9.84 & 10.97 \\
\hline
\end{tabular}

$\mathrm{T}_{\mathrm{o}}, \mathrm{T}_{1}, \mathrm{~T}_{2}, \mathrm{~T}_{3}$ and $\mathrm{T}_{4}$ were as defined in Table 1

Table 7: ANOVA for the effect of MTW on the flexural strength of concrete using RCBD.

\begin{tabular}{cccccc}
\hline $\begin{array}{l}\text { Source } \\
\text { variation }\end{array}$ & $\begin{array}{c}\text { Degree } \\
\text { freedom }\end{array}$ & of Sum of Square & Mean Square & $\begin{array}{l}\text { Calculated } \\
\text { value of } \mathbf{F}\end{array}$ & $\begin{array}{l}\text { Table value of } \mathbf{F} \\
\mathbf{a t} \mathbf{p} \leq \mathbf{1 \%}\end{array}$ \\
\hline Treatment & 4 & 3.20 & 0.800 & $7.805^{\mathrm{S}}$ & 4.430 \\
Curing day & 3 & 8.78 & 2.927 & $28.417^{\mathrm{S}}$ & 5.010 \\
Error & 12 & 1.23 & 0.103 & & \\
Total & 19 & 13.21 & 0.695 & & \\
\hline $\mathrm{S}=$ Effect was significant at $\mathrm{p} \leq 1 \%$ &
\end{tabular}

Table 8: Effect of magnetically treated water on impact resistance using $997 \mathrm{G}$ with $110 \mathrm{~s}$.

\begin{tabular}{ccccc}
\hline Curing (days) & NMTW Cracking & MTW Cracking & NMTW Failure & MTW Failure \\
\hline 7 & 27.12 & 94.92 & 88.14 & 166.62 \\
14 & 33.90 & 176.28 & 156.00 & 291.54 \\
21 & 39.00 & 198.21 & 160.01 & 301.21 \\
28 & 40.68 & 223.74 & 162.72 & 320.44 \\
\hline
\end{tabular}

concrete by $10-22 \%$. Ahmed (2009) concluded that the strength of concrete produced using magnetized water (magnetically treated water) was increased by $10-20 \%$.

The compressive strength and flexural strength obtained in this study were higher than the values obtained by other researchers which might be due to circulation flow method which was used in this study. The circulation flow method is more effective for producing MTW than the static flow method used by some researchers. The results obtained in this study agreed with the result obtained by other researchers that MTW increased the compressive strength of concrete and curing time of 7, 14, 21 and 28 days also increased the strength of the concrete. The effect of MTW was statistically significant on the compressive, flexural strengths and impact resistance which agrees with the studies by Ahmed (2009); Parthiban et al. (2016); Kiranmai and Rao (2018), Nilson (1987) reported that magnetically treated water increased the strength of the concrete by $10-22 \%$.

Ahmed (2009) concluded that the strength of concrete produced using magnetized water (magnetically treated water) was increased by $10-20 \%$ using magnetic flux density of 12,000 G. Albahrani (2018) pointed out that the compressive strength of concrete produced using magnetized water treated with magnetic field for 28 days increased by $26.2 \%$ while
Kiranmai and Rao (2018) reported that the compressive strength of concrete (M30 grade) produced using magnetized water treated for 24 hours increased by $38.1 \%$ after curing for 7 days. Parthiban et al. (2016) also concluded that magnetized water increased the compressive strength of concrete by $39.48 \%$. when the water was treated for 72 hours with a static flow method of magnetic treatment of water. The effect of MTW on the compressive and fle xural strengths of the concrete was statistically significant at $p \leq 1 \%$ as shown in Tables 3, 5 and 7 of the analysis of variance (ANOVA).

\section{CONCLUSION}

Magnetized water was produced by allowing water to flow through the magnetic field in a hose surrounded by permanent magnets. Magnetized water increased the compressive, flexural and impact resistance strengths of the concrete by $13.58-84.17 \%, 2.97-22.37 \%$ and $22.78-96.93 \%$, respectively. The effect of magnetically treated water was statistically significant on compressive, flexural and impact resistance strengths of the concrete. From this study, magnetically treated water was found to be a simple and promising technology that could be used for producing stronger concrete and sandcrete blocks. 


\section{ACKNOWLEDGEMENTS}

The authors would like to acknowledge the technical assistance provided by Engr Israel Duniya.

\section{REFERENCES}

Ahmed, S. M. (2009). Effect of Magnetic Water on Engineering Properties of Concrete. AL-Rafidain Engineering Journal. 17 (1): 71-82.

Akpenpuun, T. D.; Akinyemi, B. A.; Olamide, O.; Aladegboye, J. O.; and Adesina. O. I. (2019). Mechanical and structural characteristics of cement mortars blended with locust bean pod ash. International Commission of Agricultural and Biosystems Engineering Journal (CIGR), 21(4): 48-55. https://tinyurl.com/9nxbeb8p

Aladjadjiyan, A. (2000). The use of physical methods for plant growing stimulation in Bulgaria. Journal of Central European Agriculture, 8 (3): 369-380.

Albahrani, H. S. (2018). Improvement of mechanical properties of concrete using magnetic water with different ages of magnetism. Journal of Engineering and Applied Science, 13 (24): 10384-10387.

Chern, C. C. (2012). Application of magnetic water to stimulate the lady's finger (Abelmosculentus L.) moench plant growth. Unpublished B. Eng. Thesis, School of Civil Engineering, Faculty of Engineering, University of Technology, Johor, Malaysia.

Gomez, K. A. and A. Gomez. (1984). Statistical procedures for agricultural research. 2nd Edition, John Wiley and Sons, New York, 1-120.

Karam, H. and O. Al-Shamali. (2013). Effect of Using Magnetized Water on Concrete Properties, Third International Conference on Sustainable Constructional Materials and Technologies held at Kyoto Research Park, Kyoto, Japan on 18th - 22nd August, 2013. 1-12.

http://www.claisse.info/Proceedings.htm

Kiranmai, Y. and K. N. S. Rao. (2018). Strength Permeation and Nano Studies on Fly Ash Based Magnetic Water Concrete. International Journal of Scientific Engineering and Technology Research, 7 (6): 1088-1093.

Kronenberg, K. J. (1985). Experimental evidence for effects of magnetic fields on moving water. Institute of Electrical and Electronics Engineers Transactions on Magnetics, 21(5): 2059-2066.

Maheshwari, R. L. and H. S. Grewal. (2009). Magnetic treatment of irrigation water: its effects on vegetable crop yield and water productivity. Journal of Agricultural Water Management, 96 (8): 1229-1236.

Malathy, R.; N. Karuppasamy and S. Baranidharan. (2017). Effect of magnetic water on mixing and curing of M25 grade concrete. International Journal of Chem Tech Research,
10 (11): 131-139.

Montgomery, D. C.; Runger, G. C.; and Hubele, N. F. (1998). Engineering statistics. John Wiley and Sons, Inc, New York: 135-248.

Nan, S.; Wu, Y. H.; and Mar, C. Y. (2003). Effect of magnetic field treated water on mortar and concrete containing fly sh. Cement and Concrete Composites, 25 (7): 681-688.

Nilson, A. H. (1987). High-Strength Concrete, an Overview of Cornell Research, Proceedings Symposium on Utilization of High-Strength concrete, Stavanger, Norway, 2738.

Parthiban, P. M. E.; Rajalingam M. E.; and George, S. (2016). Comparative Study on Strength Enhancement of Concrete Using Magnetic and Normal Water. International Journal of New Technology and Research (IJNTR), 2 (5): 6568.

Patil, S. V and N. J. Pathak. (2016). The experimental study on compressive strength of concrete using AR glass fibers and partial replacement of cement with GGBS with effect of magnetic water. International Journal of Engineering Technology, Management and Applied Sciences, 4 (8): 21-29.

Podlesny, J.; Pietruszewski, S.; and Podleoena, A. (2004). Efficiency of the magnetic treatment of broad bean seeds cultivated under experimental plot conditions. International Agrophysics, 18: 65-71.

Reddy, S. B.; V. G. Ghorpade and H. S. Rao. (2014). Influence of Magnetic Water on Strength Properties of Concrete. Indian Journal of Science and Technology, 7(1): 1418.

Shynier, A; Abed, M.; Fouad, Z.; Kazim, A.; Isse, R.; Reheem, N.; Chaloob, A.; Mohammad, A.; Jamal, N.; Jasim, H.; Sadeeq, J.; and A. Salim. (2012). Improving some of mechanical properties of concrete by magnetic water technology. Proceedings of 5th Jordanian International Civil Engineering Conference (JICEC5) 17th - 19th January, 2012 held at Landmark Hotel Amman (5 stars), Amman, Jordan: 111 .

Vinod-Kumar, G.; K. Gopala and K.V. S. Sastry. (2017). Effect of magnetized water on the properties of Concrete with different pozzloanic material. Journal of Advanced Research in Dynamical and Control Systems (Special issue), 9 (14): 382-390.

Yusuf, K. O. and Ogunlela, A. O. (2016). Effect of magnetically treated water on the quality of tomato. Kathmandu University Journal of Science, Engineering and Technology, 12 (2): 29-33.

Yusuf, K. O. and Ogunlela, A. O. (2017). Effects of magnetized water on the vegetative growth and yield of tomato. Journal of Agricultural Engineering International (CIGR Journal), 19 (1): 1-8. 